\title{
Study on Bullying Status of Rural Boarding Students on Campus-Taking X Middle School as an Example
}

\author{
Xiaojie Gong ${ }^{1}$, Qiao Sun $^{2}$ and Jia Cong, ${ }^{1, *}$
}

\begin{abstract}
${ }^{1}$ School Political Science and Law University of Jinan, Jinan, Shandong 250022, China Email:1095324155@qq.com ${ }^{2}$ School Political Science and Law University of Jinan, Jinan, Shandong250022, China Email:448213433@qq.com

*Lancaster University The United Kingdom,Ph.D.Email:2428407729@qq.com
\end{abstract}

\begin{abstract}
This article is based on a cross-sectional survey and field interviews on the bullying status quo of the rural boarding school in S Province X Middle School, using the D. Olweus Child Bullying Questionnaire redesigned middle school student bullying questionnaire, and a descriptive analysis of the current situation of school bullying in X Middle School. Meta-Logistic regression analysis and Spearman's rank correlation coefficient, summarize the basic characteristics of campus bullying in rural boarding middle schools, explore the influencing factors of current campus bullying incidents in rural boarding middle schools, and explore countermeasures and suggestions to prevent campus bullying in my country.
\end{abstract}

Keywords: Campus bullying, Rural boarding schools, Middle school students

\section{INTRODUCTION}

With the development of network information technology, vicious school bullying incidents will be exposed by Internet media almost every once in a while. Whether it is the incident itself or the way the school or parents handle it, it will arouse heated discussions among the public. School bullying is a problem that every school has to face. Even in some developed countries in Europe and the United States, where the legal system is sound and civilized, the occurrence of school bullying cannot be completely eliminated. The harm of campus bullying cannot be ignored. No matter what form of bullying, it will have varying degrees or even serious adverse effects on the bullied, and sometimes it will have a bad impact on bystanders and even campus culture.

According to the data of the 21st Century Education Research Institute in 10 provinces, about $40 \%$ of primary school students in rural areas lived in schools in 2012, while $62 \%$ of junior high school students lived in schools[1]. The massive outflow of the labor population in rural areas and the reduction in fertility has led to a large reduction in the source of rural basic education students. In order to improve the quality of education and integrate resources, my country's education departments and local governments have jointly launched a large-scale "removal of sites and schools" across the country. "A large number of rural boarding schools have been established. Since then, rural boarding schools have become the main part of rural schools. Compared with ordinary schools in the city, rural boarding schools have formed their obvious particularities due to geographical, political, economic and other reasons. Rural boarding schools not only have a high boarding rate, but also have characteristics such as poor teaching environment and quality. Therefore, school bullying in rural areas should become the focus of society's attention.

\section{LITERATURE REVIEW AND RESEARCH METHODS}

\subsection{Literature Review}

From the perspective of foreign studies, bullying in school was first carried out in the professional field of psychology. In the 1970s, Dan Olweus, a Norwegian psychology professor, conducted a systematic study of bullying in schools. He believes that bullying is when a student is bullied over a long period and repeatedly by negative behavior adopted by one or more students. Negative behavior can be physical, verbal, or otherwise[2]. The definition of school bullying by D. Orlweus contains three characteristics: repetitive and long-term, negative behaviors and unbalanced strength. The British scholar P.K.Smith put forward that school bullying has the characteristics of intentionality, repeatability and power disparity[3]. Norway to counter the problem of bullying, set up Mr Chavez anti-bullying school, class and individual level intervention plan, and in 2002 published the declaration of bullying, set up the national anti-bullying alliance, at the same time start the bullying zero-tolerance scheme, guiding students, parents, school cooperation to address bullying in schools, and greatly reduces the incidence of bullying[4]. The American School Safety Center launched the "School Bullying Practice Workshop" project in 1987, emphasizing that reducing school bullying requires the participation of all actors in society[5]. The U.S. federal government and various states have adopted many strict laws and regulations related to school bullying 
to protect campus safety, such as the "Safe, Drug-Free Schools and Communities Act" and the "New Jersey Anti-Bullying Act." The promulgation of these laws in the United States has effectively reduced the incidence of school bullying.

Japan adopted the Bullying Prevention Countermeasures Promotion Act, effectively reducing the incidence of bullying on campus[6]. The definition of campus bullying in our country mainly focuses on the difference between campus bullying and campus violence.

Firstly, from domestic studies, the definition of school bullying. The existing researches on the definition of school bullying mainly focus on the difference between "school bullying" and "school violence". Secondly, about the types of bullying in school. Originally, D. Olweus divided bullying behavior into five categories in his bullying behavior questionnaire, namely verbal bullying, physical bullying, relationship bullying, sexual bullying and cyber bullying[7]. Wang Yuxiang studied the school bullying of left-behind teenagers in rural areas in China, and believed that the types of school bullying of left-behind teenagers in rural areas were power type, dignity type, friendship type and jealousy type[8].Shi ping Classified school bullying into five categories: fighting, extortion, bullying, sexual violence and murder[9]. Thirdly, research on the characteristics, influencing factors and countermeasures of school bullying. Large-scale empirical studies on school bullying in China mainly focus on urban areas[10]. Most of the data analysis the phenomenon of school bullying in urban areas, while there are few studies on school bullying in rural areas, which only accounts for $0.96 \%$ of the total research on school bullying in CnKI. From the perspective of sociology, this paper focuses on the problem of school bullying in rural areas, hoping to further enrich the research on the problem of school bullying in China.

\subsection{Research Methods}

\subsubsection{Identification and Research Methods of Questionnaires and Survey Samples}

This article designs a school bullying questionnaire and interview outline for middle school students. This questionnaire is based on the reference to the D. Olweus Child Bullying Questionnaire (Secondary School Edition), which is integrated, revised, and evaluated. This questionnaire contains 4 dimensions of personal, family, school and campus safety, with a total of 45 items.

This paper uses the current situation study method to calculate the sample size. The bullying rate of middle school students on campus is $\mathrm{p}=50.57 \%$ [11], allowable error $\mathrm{d}$ is set to $0.15 \mathrm{p}$. Considering the possible non-response rate is $15 \%$, the final sample size is 192 people calculated by referring to the formula. The calculation formula is as follows:

$$
n=\frac{z_{a}^{2} \times p q}{d^{2}}
$$

Type(1)p is the expected bullying rate, $q=1-p$ according to the relevant literature, select $\mathrm{p}=0.5057, \mathrm{q}=0.4943$, The $\mathrm{d}$ is the allowable error this study is set as $\mathrm{d}=0.5 \mathrm{p}, \mathrm{Za}$ the normal distribution boundary value of 0.05 , and the $n$ is sample size. The survey adopted a cluster sampling method to sample high school students from X middle schools in $\mathrm{S}$ province. The specific sampling steps are: first use random sampling method to select 6 classes from the 36 classes of $\mathrm{X}$ middle school, a total of 1800 high school students, and then use R software to extract the random seed number of the first-class 180, and draw to the first-class After that, the remaining 5 classes were selected in turn according to the sampling interval of 300 people. The final 6 classes have 94 students in the first grade, 98 students in the second grade, and 100 students in grade three. Fill out the questionnaire and collect data. The total number of people surveyed was 292, and 18 invalid questionnaires were eliminated. A total of 274 valid questionnaires were returned, with a response rate of $93.8 \%$.

Since the questionnaire survey can only understand the general situation of the whole, in order to take into account the differences and uniqueness of the survey subjects, this study selects 8 students as the survey subjects for in-depth interviews, using questionnaire interviews, online interviews, etc. School bullying attitudes and coping strategies.

\subsubsection{Survey Subjects and Basic Demographic Characteristics}

The subjects of this study are high school students in $\mathrm{X}$ middle school in $\mathrm{S}$ province. The school currently has three grades. The middle school is located in the township area where it is located. The high school entrance in the location is based on the high school entrance examination results. Therefore, the students of this school have low school entrance examination results. Most of the students in this school have rural hukou, but there are still a small number of students with urban hukou. The school is a full-time boarding school. In order to take care of students who are far away from home and school, the school is closed every two weeks, and the vacation time is two and a half days. According to the school's regulations, all students should live on campus during school, but there are still some students who choose not to live on campus for personal reasons.

There are three main reasons for choosing this school as the survey object of this study: First, due to special factors above this school, there are "boarding students" and "non-boarding students", "rural household registration" and "non-rural household registration" in this school. The differences between the students provide favorable conditions for the investigation of the relationship between the accommodation situation, the household registration situation and the bullying behavior of the students and the bullying behavior encountered in this study. The middle 
school divides the classes of each grade into key classes and ordinary classes according to their grades. Dividing classes according to academic performance also provide favorable conditions for this study to explore the relationship between student performance and bullying experience. Second, the research on campus bullying is mostly on the campus of elementary and middle schools, and there is little research on high school students, which is conducive to in-depth interview research by investigators. Third, X Middle School is located in the author's hometown, which is conducive to the pre-investigation of campus bullying incidents and small-scale pre-investigations. After obtaining the consent of school leaders and students' parents, the school was finally selected as the research site for this study.

There are 274 respondents in this questionnaire survey, and their demographic characteristics are as follows:

Grade: 90 people in the first grade, accounting for $32.8 \%$ of the total number of the survey; 93 people in the second year, accounting for $33.9 \%$ of the total number of the survey; 91 people in the third year, accounting for $33.2 \%$ of the total number of the survey.

Gender: 138 males, accounting for $49.6 \%$ of the total survey number; 136 females, accounting for $50.4 \%$ of the total survey number.

Household registration: Rural household registration students accounted for $92 \%$ of the total survey; only $8 \%$ of students have urban household registration.

Only child: $74.5 \%$ of students are only child.

Family status: $8.9 \%$ of students come from single-parent families.

Accommodation: $21.5 \%$ of students choose day school.

Family economic status: $73.7 \%$ of students have a medium family economic status, and students with relatively rich and poor families account for $5.5 \%$ and $20.8 \%$ respectively.

In addition to 274 valid questionnaires, the survey also conducted interviews with 8 relevant students. (As is shown in Table 1)

Table 1. The basic situation of interviewed students

\begin{tabular}{|l|l|l|l|l|l|}
\hline Code & High school & Gender & Census Register & Only Child & Bullying Role \\
\hline A & grade one & Female & rural area & Y & Bully \\
\hline B & grade two & Female & rural area & N & Bullied \\
\hline C & grade one & Female & city & N & Bystander \\
\hline D & grade one & male & rural area & Y & Bully \\
\hline E & grade one & male & rural area & N & Bully \\
\hline F & grade two & male & rural area & N & Bullied \\
\hline G & grade two & male & rural area & N & Bullied \\
\hline H & grade third & male & rural area & N & Bystander \\
\hline
\end{tabular}

Note: Used value 1 to tabulate the binary group.

\section{ANALYSIS OF THE CURRENT SITUATION OF BULLYING IN RURAL BOARDING MIDDLE SCHOOL STUDENTS}

\subsection{Bullying on Campus in Rural Residential Middle School Students}

From the perspective of bullies, $9.9 \%$ of students have bullied others. Among them, $85.2 \%$ of the bullies and the bullied are in the same grade, $40.7 \%$ of the bullies and the bullied are classmates, and $44.4 \%$ of the bullies and the bullied are in the same grade but in different classes. About $30 \%$ of bullies have bullied both boys and girls.

From the perspective of the bullied, $25.2 \%$ of the students have been bullied. Among them, $91.3 \%$ of the students were in the same grade as the bully, $55.1 \%$ were in the same class as the bully, and $36.2 \%$ were in the same grade but different classes. $56.5 \%$ of students have been bullied by boys, $33.3 \%$ have been bullied by girls, and $10.1 \%$ have been bullied by boys and girls. In campus bullying, the two roles of the bully and the bullied are often transformed into each other. Of the 274 students in this survey, 13 of the surveyed are both bullies and bullies.

\subsection{Characteristics of Bullying on Campus of Rural Boarding Middle School Students}

\subsubsection{Types of Bullying on Campus}

The main types of school bullying in X Middle school are physical bullying, verbal bullying and relationship bullying, among which physical bullying accounts for $36.6 \%$ higher than other types. However, cyber bullying, as a product of the new era, has gradually increased in the cases of middle school bullying in recent years, which also deserves our attention. (As is shown in Table 2) 
Table 2. Main types of bullying in secondary schools

\begin{tabular}{|l|c|c|c|}
\hline & Number of cases (Person) & Percentage (\%) & Percentage of cases(\%) \\
\hline $\begin{array}{l}\text { Verbal bullying } \\
\text { (insults, threats, bad words, etc.) }\end{array}$ & 181 & 28.6 & 66.1 \\
\hline $\begin{array}{l}\text { Physical bullying } \\
\text { (pushing, bumping, fighting, etc.) }\end{array}$ & 231 & 36.6 & 84.3 \\
\hline $\begin{array}{l}\text { Relationship bullying } \\
\text { (cold violence, exclusion, isolation, etc.) }\end{array}$ & 117 & 18.5 & 42.7 \\
\hline $\begin{array}{l}\text { Cyberbullying } \\
\text { (using the Internet to spread rumors, etc.) }\end{array}$ & 9 & 1.4 & 3.3 \\
\hline Sexual abuse & 4 & 7.0 & 1.5 \\
\hline $\begin{array}{l}\text { Bullying } \\
\text { (being instructed to run errands, do homework) }\end{array}$ & 44 & 7.1 & 16.1 \\
\hline $\begin{array}{l}\text { Property bullying } \\
\text { (destruction of personal effects, money, etc.) }\end{array}$ & 45 & 0.2 & 16.4 \\
\hline Else & 1 & 0.4 \\
\hline
\end{tabular}

Note: Tabulation the binary by using value 1

\subsubsection{Forms of school bullying}

At present, the main forms of school bullying are "many-to-one", "man-to-many", "one-to-one" and "one-to-many". There are differences between males and females in X Middle school. For boys and girls, 46.7 percent and 27.7 percent of boys and girls chose "many-to-many" bullying. The ratio of male to female bullying was $20.8 \%$ and $16.8 \%$, respectively. In the other two forms, the proportion of male and female students is similar.

\subsubsection{Place of Campus Bullying}

Among the bullying incidents in $\mathrm{X}$ secondary schools , $23.8 \%$ and $22.6 \%$ of bullying incidents occurred in dormitories and bathrooms. And more than 50\% of respondents believe that these two places are the main place of campus bullying. Because the dormitory and bathroom are far from the teacher's sight, hidden, is also easy to neglect in school safety management. The survey found that $34.3 \%$ of students believe that campus bullying occurs in entertainment places around the school.

\subsubsection{Time of Campus Bullying}

According to the survey data, 76.3 percent of bullying incidents at X Middle School occurred after students returned to their dorms at night. Some 39.8 percent and 39.1 percent of the respondents said bullying occurred on the way to and from school and during recess. About 50\% of the students surveyed do not understand the duration and frequency of bullying incidents, which on the one hand indicates that bullying is hidden, on the other hand indicates that many students pay less attention to bullying on others. According to the interview results, the duration of bullying among classmates ended when the bully and the bullied were separated into different classes, and the frequency of bullying was different, irregular and random.

\subsubsection{Consequences of Bullying on Campus}

According to the survey data, in X Middle School, 34.0\% people believe that bullying will cause psychological harm to the bullied, and $25.2 \%$ think that bullying will cause physical harm to the bullied. In addition, 13.7 percent believed that bullying made the bully more aggressive, 13.6 percent believed that bullying caused the victim to retaliate against society, and 10.7 percent believed that bullying made the school atmosphere worse. Bystanders will fear the bully when they see the bullying behavior, which makes the bully more rampant. There is no doubt that the consequences of school bullying are very bad and far-reaching. Some teens, after seeing bullying as bystanders, imitate the behavior of the bullies, which is potentially harmful to the school environment.

\subsection{Analysis on the Difference of Campus Bullying}

Bullying in Rural Residential Middle School Students there were significant differences in the types of household registration, accommodation and stay-at-home behaviors among rural boarding students $(\mathrm{P}<0.05)$.

\subsubsection{Household Registration Differences}

Bullying behavior of $\mathrm{X}$ school students on campus is different among students with different household registration $(\mathrm{P}<0.05)$. The bullying $\operatorname{rate}(26.6 \%>9.1 \%)$ and bullying $\operatorname{rate}(10.3 \%>4.5 \%)$ of rural household students were higher than that of urban household students. 


\subsubsection{Accommodation Variance}

Boarding students have more opportunities to interact with others on campus than non-boarding students, so they are more likely to be involved in bullying. $\mathrm{X}$ school middle school student campus bullying in the accommodation situation has a difference. Whether or not they have been bullied in school, the probability of bullying of resident students is $16.9 \%$ age points higher, and whether they have bullied others on campus, the probability of bullying of resident students is $3.9 \%$ age points higher than that of runaway students.

\subsubsection{Left-behind Differences}

The survey data show that there are obvious differences between left-behind students and non-left-behind students in the bullying rate. In terms of bullying rate, the bullying rate of left-behind students is $30.4 \%$ higher than that of non-left-behind middle school students. The bullying rate of left-behind students is $6.5 \%$ higher than that of non-left-behind middle school students.

\subsection{Response to Bullying in Rural Boarding Schools}

\subsubsection{Bullying Responses}

When faced with bullying incidents, $60 \%$ of students chose to find a teacher to solve them, $39.4 \%$ of students chose to ask their parents for help, $32.8 \%$ chose to talk to classmates and friends, $19 \%$ chose to call the police, and $17.9 \%$ chose Solve conflicts with the bully in private. If they are bullied, $58.0 \%$ of the students will solve the problem by themselves because the bullying is not serious; $29.2 \%$ of the students think that speaking out the bullying incident that happened to them will not solve the problem; $23.4 \%$ of the students will be afraid of further retaliation by the bully Don't dare to report to teachers, parents or the police; $18.2 \%$ of students are at a loss; $17.9 \%$ of students choose to swallow their anger when faced with threats from bullies.

\subsubsection{Feelings and Practices of Bystanders}

Bystanders refer to students who know, witness, or intervene in bullying on campus. When the respondents "faced the mood of bullying on campus", more than 55\% of the people were a little angry at bullying on campus, and $26.3 \%$ of the people held an onlooker attitude towards bullying, thinking that they had nothing to do with themselves. There were $14.2 \%$ people feeling very angry. In addition, $2.9 \%$ of respondents thought bullying was interesting.

The results of "campus bullying practices" showed that the attitude of choosing should help the bullied person accounted for $66.8 \%$, which is equivalent to the proportion of "a little angry" and "very angry" in the response to "campus bullying" mentioned earlier(69.7\%). It also suggests that this group, which may be angry about campus bullying, plays a positive role in campus bullying.

\subsubsection{Teacher's Approach}

In a school, the attitudes and practices of teachers and school authorities toward campus bullying have an important impact on the school's internal environment and atmosphere. The attitude of $\mathrm{X}$ middle school teachers towards campus bullying appears to be relatively negative on the whole, and some teachers have insufficient awareness of campus bullying. As shown in the table below, only $56.2 \%$ of teachers will promptly stop and criticize the behavior when encountering student bullying. $23.7 \%$ are silent and do not express their opinions, $13.1 \%$ support bullying, don't know, no $6.6 \%$ have encountered this situation.

\subsubsection{School Preventive Measures}

Preventing school bullying requires every young person to have legal knowledge and self-protection awareness. Survey data shows that $\mathrm{X}$ Middle School conducts ideological and moral education and mental health education, legal education, self-protection education, and school bullying safety education less frequently, generally once a year or once a semester.

\section{CONCLUSION}

Through the binary logistic regression analysis and Spearman's rank correlation coefficient of school bullying and bullying of middle school students, the results show: First, the grade, the number of good friends, the status of staying behind, and parental care are negatively related to the situation of being bullied, while the relationship with the father is positively related to the situation of being bullied;

Second, students' academic performance and relationship with their mothers are positively correlated with bullying on campus, while parental care is negatively correlated with bullying others;

Third, the most significant factors affecting middle school students' bullying are at the individual level and family level. The school level and social level have relatively little impact.

\section{REFERENCES}

[1] 21st Century Education Research Institute. The current situation and future development trend of rural education in China [R]. 2013-11-01.

http://www.21cedu.org/ 
[2] Owleus.D. A Profile of Bullying at Schoo [J]. Educational Leadership, 2003, Vol.60:12-17.

[3] Smith, P.K. Bullying in Schools: Lessons from Two Decades of Research[J]. Aggressive Behavior, 2000, Vol. 26:1-9.

[4] Del Stover. Treating Cyberbullying as a School Violence Issue [J].The Education Dige St, Dec 2006.

[5]Is campus bullying in Japan really that exaggerated? [N]. Sohu.com.2018-11-14. http://m.souhu.com

[6] Don Fraer. Procative Prevenion[J].American school University, Feb 2007.

[7] Peng Yanling. Discussion on the effectiveness of intervention in life skills teaching against bullying on campus[J]. Taiwan: National Taiwan Normal University, 2009.
[8] Wang Yuxiang. A qualitative study on the problem of campus bullying of left-behind youth in rural areas[J]. Chinese Youth Research, 2016(12): 63-68.

[9] Shi Ping. A Probe into the Problem of School Violence in Rural Middle Schools-A Case Study of Lingkou Middle School in Lintong District, Xi'an[J]. Talent, 2013(21): 28-29.

[10] Teng Hongchang. Yao Jianlong.A Study on the Influencing Factors of School Bullying in Primary and Secondary Schools - Based on a survey of more than 100, 000 primary and middle school students nationwide[J]. Educational Science Research, 2018(03): $5-11+23$

[11] Zhang Bingjuan. Research on the Causes and Preventive Countermeasures of Middle School Student Bullying - Based on the Analysis of Social Control Theory [D]. Southwest University, 2018. 